http://dx.doi.org/10.35381/r.k.v4i1.460

\title{
La lógica difusa como herramienta de evaluación financiera de proyectos de inversión
}

\author{
Fuzzy logic as a financial evaluation tool for investment projects
}

Kleber Patricio Vidal Beltrán

kvidalb@psg.ucacue.edu.ec

Universidad Católica de Cuenca

Ecuador

https://orcid.org/0000-0001-8524-0422

Juan Carlos Erazo Álvarez

jcerazo@ucacue.edu.ec

Universidad Católica de Cuenca

Ecuador

https://orcid.org/0000-0001-6480-2270

Cecilia Ivonne Narváez Zurita

inarvaez@ucacue.edu.ec

Universidad Católica de Cuenca

Ecuador

https://orcid.org/0000-0002-7437-9880

Recibido: 10 de agosto de 2019

Aprobado: 30 de agosto de 2019

\section{RESUMEN}

Ecuador es un país con gran variedad de productos alimenticios con alto valor nutricional y sensorial que según datos de organismos estatales tiene una creciente orientación poblacional hacia el cuidado de la salud, el bienestar, el cuidado ecológico y los estilos de vida activa, lo que sugiere la existencia de un gran potencial en el mercado de alimentos deshidratados como snacks saludables de diversas frutas, productos de repostería, té herbal para infusiones, especierías, condimentos de cocina, materia prima para elaboración de otros productos alimenticios ente otros, consecuencia de lo cual se realizó la presente investigación para diseñar un proyecto de inversión dedicado a la producción y comercialización de alimentos deshidratados con alta penetración en el 
mercado Cuencano. La investigación fue de tipo aplicado, no experimental y de corte transversal, lograda aplicando lógica difusa como herramienta de evaluación financiera, misma que permitió optimizar la asignación de recursos incrementando la rentabilidad.

Descriptores: Lógica; Difusa; Evaluación Financiera; Proyecto; Inversión

\begin{abstract}
Ecuador is a country with a wide variety of food products with high nutritional and sensory value that according to data from state agencies has a growing population orientation towards health care, well-being, ecological care and active lifestyles, which suggests the existence of great potential in the market for dehydrated foods such as healthy snacks of various fruits, pastries, herbal tea for infusions, specimens, cooking condiments, raw material for the preparation of other foodstuffs among others, as a result of which $\mathrm{He}$ carried out the present investigation to design an investment project dedicated to the production and commercialization of dehydrated foods with high penetration in the Cuenca market. The research was applied, non-experimental and cross-sectional, achieved by applying fuzzy logic as a financial evaluation tool, which allowed optimizing the allocation of resources by increasing profitability.
\end{abstract}

Descriptors: Fuzzy; Logic; Financial Evaluation; Project; Investment.

\title{
INTRODUCCIÓN
}

Según datos de la Corporación Financiera Nacional (2017) la mayor industria del Ecuador se encuentra en el sector de elaboración de alimentos y bebidas, ocupando un 38,0\% del sector manufacturero, esto debido a que en Ecuador se generan gran variedad de alimentos con características propicias para el desarrollo a nivel industrial, cuya evolución depende de la demanda interna y de las medidas de comercio exterior adoptadas por el gobierno nacional, destacando el hecho de que dentro de la industria de los alimentos, las producciones más grandes, conforme lo recoge la revista Ekos (2018) con datos del Banco Central del Ecuador son: procesamiento y conservación de pescado, camarones y otras especies con el $27 \%$, bebidas $15 \%$, productos cárnicos $14 \%$, grasas y aceites $10 \%$, productos lácteos $8 \%$, panadería $6 \%$, molinería $4 \%$ y otros productos alimenticios $16 \%$. 
Por otra parte, según datos del Servicio de Rentas Internas (2019) el entorno de la industria de alimentos deshidratados en la provincia del Azuay actualmente tiene un muy bajo protagonismo, ya que existen registradas únicamente 14 empresas activas cuyas actividades económicas se encuentran relacionadas con la conservación de frutas, legumbres y hortalizas mediante el congelado, secado, deshidratado, inmersión en aceite o vinagre, enlatado, entre otros.

Cabe indicar que la presente investigación se encuentra estrechamente relacionada con los objetivos y políticas del Plan Nacional de Desarrollo del Ecuador 2017-2021 Toda una Vida, específicamente con la política 6.3: Impulsar la producción de alimentos suficientes y saludables, así como la existencia y acceso a mercados y sistemas productivos alternativos, que permitan satisfacer la demanda nacional con respeto a las formas de producción local y con pertinencia cultural.

Ahora bien, analizando el entorno interno en Ecuador, existe la ANFAB Asociación Nacional de Fabricantes de Alimentos y Bebidas que otorga a sus miembros servicios de representación, información, asesoría técnica y capacitación. La ANFAB representa a las empresas agroindustriales y productoras de alimentos del Ecuador que conforman el sector industrial más relevante y dinámico del país, esta entidad, sin fines de lucro, contribuye al desarrollo sustentable de la agroindustria, promoviendo la competitividad, los procesos de calidad y la inocuidad de la cadena productiva para beneficio del consumidor (ANFAB, 2019).

Tomando en cuenta todo el antecedente mencionado, la presente investigación tiene como objetivo evaluar financieramente un proyecto de inversión mediante la utilización de lógica difusa, también conocida como lógica borrosa que permita determinar la viabilidad del proyecto de producción y comercialización al por mayor de alimentos deshidratados englobados en tres líneas de productos: los mix de frutas deshidratadas como snacks, té para infusiones y especierías de cocina, que opere con una planta de producción que utilice métodos, técnicas, maquinaria, equipos e instrumentos con enfoque ecológico y medioambientalmente sostenible. 
Para tal efecto se plantea que la micro empresa sea de carácter privado, con sede en la ciudad de Cuenca y con influencia a nivel nacional e internacional, por lo que deberá cumplir con estándares de calidad tanto nacionales como internacionales y tener cobertura en varias provincias del Ecuador, siendo su mercado meta principal la zona austral de nuestro país.

\section{Los proyectos de inversión como eje fundamental del emprendimiento}

Dentro de la literatura consultada como sustento teórico de la presente investigación existe una gran cantidad de autores que expresan sus criterios acerca de lo que es un proyecto de inversión, por lo cual en la tabla 1 se han recogido los criterios más relevantes y aclaratorios.

\section{Tabla 1}

Definiciones de proyecto de inversión

$$
\text { Autor (año) }
$$

\section{Definición}

Flórez (2017) Es el desarrollo de una idea inteligente encaminada a producir bienes o servicios tendientes a satisfacer las necesidades de los consumidores a la vez que se alcanzan objetivos propuestos de tipo económico, social y organizacional, de tal manera que permita el futuro crecimiento y expansión de la empresa.

Sapag (2011) Un proyecto de inversión se centra en recopilar, crear y sistematizar información relevante que permita la identificación de ideas de negocios, así como medir de forma cuantitativa los costos y los beneficios de un proyecto comercial, considerando que igual importancia tiene el contar con recursos suficientes para invertir que el hecho de asignarlos racionalmente.

Goercke, Erazo, Es un documento escrito que describe en detalle cómo una empresa, Narváez y generalmente una nueva, va a lograr sus objetivos, establece un plan Quevedo (2019) redactado desde un punto de vista de marketing, financiero y operativo.

Andía y Paucara Se entiende como el accionar en un medio determinado para (2013) solucionar los problemas identificados a la vez que se alcanzan los objetivos planteados. 
CEASE Centro de apoyo al sector empresarial (2011) Weinberger (2009)
Instrumento de gestión empresarial que sirve de guía para que el emprendedor o empresario implemente un negocio, considerándose también como un instrumento de planificación que permite transmitir una idea de negocio para gestionar su financiamiento.

Es una herramienta de comunicación escrita que tiene esencialmente dos funciones: una que se puede llamar interna o administrativa que comprende todo lo que se requiere y otra que es conocida como externa y comprende todo lo financiero

\section{Utilidad de un proyecto de inversión}

Según expresa Décaro (2015) el proyecto de inversión mediante los estudios administrativos, productivos, mercantiles y financieros previamente realizados se encuentra enfocado a indicar la manera como trabajará la empresa, otorgando la capacidad de identificar la viabilidad de creación de un nuevo emprendimiento, trazando un camino para que la empresa pueda alcanzar sus metas, así como también contendrá información precisa sobre la manera en que la empresa funcionará en un plazo establecido, brindando de esta manera la información necesaria para conocer la rentabilidad pronosticada de un nuevo emprendimiento, generando alertas y brindando alternativas de mejora, Martínez \& El Kadi (2019), destacan la importancia del proyecto como logística organizacional, mientras que Chirinos (2016), señala que es importante que el proyecto contemple el componente innovación como factor de crecimiento organizacional.

Mientras tanto Díaz (2014) refiere que el proyecto de inversión tiene por objetivo describir e informar el detalle de cómo, cuándo y cuáles serán los recursos necesarios para implementar un proyecto específico.

Dentro de este marco, al definir cuáles son las variables más importantes del negocio, puede ser una muy buena referencia cuando se necesite medir el progreso del proyecto de inversión.

De igual manera, sirve como una herramienta que facilita su involucramiento y motivación de todo el equipo de emprendedores, así posibilita también la identificación 
de la capacidad de los partícipes para alcanzar el éxito empresarial, así como sus habilidades enfocadas a minimizar los riesgos que se pueden producir por su giro de negocio, permitiendo así atraer recursos, financiamiento y alianzas estratégicas.

En tal virtud, esta herramienta puede ser utilizada no sólo en el génesis empresarial, sino también puede utilizarse en empresas ya constituidas y en operación que requieran ser partícipes de nuevos mercados, apreciándose así la utilidad de un proyecto de inversión en la ayuda que brinda para conocer detalladamente el negocio, sus antecedentes, las estrategias, factores de éxito o fracaso y las metas que persigue.

\section{Características y estructura del proyecto de inversión}

Bravo y Cárdenas (2016) expresan que las características que debe tener un proyecto de inversión son las siguientes:

Ser claro, concreto y conciso.

Brindar una guía a la organización para alcanzar sus objetivos.

Estar alineado a la realidad económica, social, política, ambiental, tecnológica, competitiva y cultural del entorno en la que se efectuará la inversión.

Ser extensa y completa, englobando todas las áreas organizativas y sus capacidades.

Debe incentivar la interacción participativa de los involucrados en la gestión y arranque del proyecto.

Debe ser una guía bien documentada y una fuente de consulta para todos los involucrados internos y externo de la organización.

También debe guardar armonía con los ambientes complejos, variables y competitivos.

Finalmente debe ser flexible, permitiendo al emprendedor realizar ajustes y retroalimentaciones al proyecto de inversión cuando lo amerite, de conformidad con las condiciones y circunstancias a las que se enfrente la organización.

Castillejo (2015) opina que un proyecto de inversión se encuentra constituido por planes internos de cada área funcional de una futura organización, deberá contemplar un plan de marketing, un plan de producción, un plan logístico, un plan económico financiero y 
un plan de recursos humanos, claro que se debe considerar que no todos los planes de negocios tienen detallado cada plan interno, incluso no todos los negocios cuentan con todas las áreas funcionales de una empresa.

\section{Importancia de la evaluación financiera en los proyectos de inversión}

Según indican Viñan, Puente, Ávalos y Córdova (2018) el análisis financiero tiene por objeto determinar los recursos monetarios necesarios para ejecutar un determinado proyecto de inversión, identificando los costos de operación, de producción, administrativos y de ventas entre otros.

Es por ello que una correcta evaluación financiera puede marcar el éxito o el fracaso de un proyecto de inversión, ya que una incorrecta asignación de recursos o una excesiva confianza en el proyecto puede revertirse en un sobreendeudamiento, un déficit presupuestario o la obtención de márgenes de utilidad muy deficientes que no permitan a la empresa avanzar en la consecución de sus objetivos propuestos.

Así la evaluación financiera alcanza una gran importancia en la toma de decisiones, debido a que a través de los indicadores correspondientes se establece el nivel de cumplimiento de las metas, que los recursos se hayan utilizado eficiente, correcta y eficazmente, sin subutilización o asignación a procesos ociosos y así tener una base para tomar los correctivos necesarios.

\section{La lógica difusa como aporte a la evaluación financiera}

La lógica difusa es un método dinámico de gestión empresarial que capta la realidad, recoge lo objetivo, lo subjetivo y los elementos que pueden producir variación a lo largo de los años, ayudando a mejorar la calidad y el tratamiento de la información económica, contable y financiera de una determinada empresa, pudiendo ser utilizado en cualquier unidad de análisis independientemente de su giro de negocio.

Al mismo tiempo, la lógica difusa se puede utilizar en distintas áreas del conocimiento, la importancia de los modelos matemáticos que presenta es que permite atrapar la 
incertidumbre y así obtener resultados más cercanos a la realidad, por lo que, en el ámbito empresarial da paso a un eficaz proceso de toma de decisiones económicas y financieras en el que las variables no son estáticas como en la forma tradicional. Atendiendo a estas consideraciones Rico y Tinto (2008) manifiestan que a pesar de que en las ciencias contables se continúan utilizando los sistemas de parámetros lineales que incorporan incertidumbre, subjetividad y lo impreciso de la dinámica económica actual, lo que ha generado que en la realidad tenga poca confiabilidad para una toma de decisiones acertada, es posible concebir y manifestar los resultados de las operaciones mercantiles de otra forma, una forma dinámica mediante matemática borrosa aplicada a los datos otorgadas por la forma tradicional de hacer contabilidad, lo cual permitirá aumentar la fiabilidad de los datos y optimizar de esta manera el proceso de toma de decisiones racionales y creativas en un plazo establecido.

Así pues, en la época actual se han presenciado constantes cambios en el ámbito empresarial e industrial las cuales están sujetas a frecuentes transformaciones con la implementación de nuevas tecnologías, representando un gran reto al considerar que se debe realizar un extenso análisis de la información generada por las empresas y el procesamiento de dicha información de una forma ágil y dinámica, procurando disminuir al máximo la incertidumbre y el riesgo formado en gran medida por la globalización de los mercados.

Al mismo tiempo, uno de los mayores retos de las empresas en estos días es el alcanzar la eficiencia y a su vez ser competitiva, de esta forma y dentro del ámbito de la gestión empresarial se usan herramientas como la lógica difusa que utiliza técnicas como el tratamiento en bandas, el expertizaje,y el contraexpertizaje entre otras, que permiten identificar la movilidad de los fenómenos económicos y la relación entre las variables que intervienen en la empresa y que permiten desarrollar estrategias apropiadas con el fin de alcanzar los objetivos empresariales a través de la toma de decisiones adecuadas En consecuencia, se puede determinar que el expertizaje y contra expertizaje en la empresa es una técnica que permite reducir la incertidumbre a través de la recolección 
de datos por medio de la opinión de los expertos recogidas a través de la aplicación de encuestas diseñadas para que puedan indicar sus criterios, siendo éstos presentados en bandas. (Sánchez, Luna, Narváez y Erazo, 2019)

Sobre las bases de las ideas expuestas, la metodología de la transformación en valoración empresarial de lo estático a lo dinámico cuenta con los siguientes pasos:

Primer paso: se busca un conjunto de expertos en el giro del negocio a los que se les va a preguntar sobre cada una de las cuentas de interés que presenten incertidumbre, cuáles serían la cota más baja o pesimista y la cota más alta u optimista que pueden tomar durante los próximos años.

Segundo paso: obtenidos esos valores se crea un "intervalo de confianza" que comprende dos bandas para cada cuenta, ubicando los valores más bajos a la izquierda (A) y los valores más altos a la derecha $\left(A^{*}\right)$, esto se logra haciendo "caer la entropía", lo que consiste en sumar el valor mayor y el valor menor que dieron los expertos para cada cuenta y dividirlos para dos.

Tercer paso: para cada una de las cuentas, se construye el expertón con una escala endecadaria del cero al uno, donde refleja que tan de acuerdo esta cada uno de los expertos en que suceda lo propuesto para cada una de las cuentas.

Cuarto paso: se realiza el "vaciado de valores" que comprende el colocar cuantas veces se repite cada uno de los valores de la escala endecadaria en la opinión que han asignado los expertos, esto se lo realiza para cada una de las bandas.

Quinto paso: se procede a "normalizar la serie" dividiendo cada uno de los valores del vaciado para el total (dicho valor total es el mismo del número de expertos), se lo realiza igualmente para las dos bandas.

Sexto paso: se crea el "expertón alpha" mediante la acumulación desde abajo hacia arriba de los valores obtenidos en la normalización.

Séptimo paso: se realiza el "contraexpertizaje" utilizando la fórmula: $A+\left(A^{*}-A\right)$ alpha donde A es el valor de la banda izquierda de la dupleta correspondiente a la cuenta que se está analizando, $A^{*}$ es el valor correspondiente a la banda derecha de la mencionada dupleta 
y Alpha es el valor del "expertón alpha" obtenido en el paso anterior (González, Luna, Erazo y Sarmiento, 2019).

De esta manera se obtienen los valores reales de las bandas para cada una de las cuentas, de forma dinámica, con el mínimo nivel de incertidumbre y con mayor confianza que con la forma tradicional estática de análisis financiero.

\section{METODOLOGÍA}

La investigación fue aplicada con un diseño de tipo no experimental, corte transversal debido a que la información se levantó una sola vez utilizando la técnica de encuestas y se determinó que la presente investigación tiene carácter mixto con un enfoque cuantitativo en el que se recogieron los datos necesarios para medir los fenómenos estudiados, estos se presentaron numéricamente y se analizaron con métodos estadísticos, así también tiene un enfoque cualitativo ya que al tratarse de temas sociales se pretendió estudiar a detalle los componentes que intervienen otorgando perspectivas subjetivas y no tan estructuradas que se obtuvieron a partir del enfoque cuantitativo y de la interacción del investigador y el objeto

Se estableció que la presente investigación es descriptiva, debido que se describieron los fenómenos y cómo se comportan en el mercado, delimitando y segmentando el mercado al que se dirige y del cual se deseaba obtener la información.

Para la presente investigación, se empleó el método inductivo-deductivo, que, en base al diseño y ejecución de una entrevista al inversionista, aportó al cumplimiento de los objetivos planteados.

Al obtener datos mediante la encuesta, se utilizó el método histórico-lógico mediante la revisión de la correspondiente literatura en la que se basó el desarrollo del marco teórico, así como del estado de la situación en la que se respalda la presente investigación. También fue empleado el método analítico-sintético mediante el diseño, ejecución y procesamiento de los datos de las encuestas, enfocadas al cumplimiento de los objetivos planteados en el presente estudio. 
Como instrumentos de investigación de las encuestas se utilizaron los cuestionarios estructurados.

Mediante la aplicación de la fórmula establecida por López y Fachelli (2015) para cálculo de muestras de poblaciones finitas mediante el método probabilístico de muestreo aleatorio simple, cuyo significado y valores de variables se muestra en la tabla 2 se estableció que en el presente estudio se debían aplicar 384 encuestas.

\section{Fórmula de muestreo aleatorio simple}

$$
n=\frac{z^{2} \times P \times Q \times N}{(N-1) \times e^{2}+z^{2} \times P \times Q}
$$

\section{Significados y valores de las variables utilizadas}

\section{Tabla 2}

\begin{tabular}{clr} 
Variable & \multicolumn{1}{c}{ Significado } & Valor \\
\hline $\boldsymbol{n}$ & Tamaño de la muestra & \\
$\boldsymbol{Z}^{2}$ & Nivel de confianza elevado al cuadrado & 1,96 \\
$\boldsymbol{e}^{2}$ & Error muestral considerado elevado al cuadrado & 0,05 \\
$\boldsymbol{N}$ & Número total de la población o universo de estudio & 225.635 \\
$\boldsymbol{P}$ & Proporción de la población que tiene una característica buscada & 0,5 \\
$\boldsymbol{Q}$ & Proporción de la población que no tiene una característica buscada & 0,5 \\
\hline
\end{tabular}

\section{RESULTADOS}

Mediante la aplicación de encuestas para la recolección de datos a través de un cuestionario que se aplicó personalmente al mercado objetivo: supermercados, tiendas y restaurantes ubicados en el área urbana de la ciudad de Cuenca, considerando como universo de estudio a hombres y mujeres del área urbana de Cuenca con ingresos superiores a $\$ 1000$ distribuidos en los quintiles 4 y 5 de acuerdo con los datos recogidos en el INEC (Matriz de resultados ENIGHUR) al 2012 eran 196.204 personas como la ciudad presenta un crecimiento poblacional del 15\% en 7 años al 2019 se proyectan 
225.635 personas en los quintiles 4 y 5 con ingresos per cápita a partir de $\$ 1096$. En base a las respuestas obtenidas, se determinó los siguientes resultados:

En el universo de estudio existe un muy alto porcentaje de consumo de alimentos deshidratados $(82,3 \%)$, con un similar interés por los tres tipos de productos ofertados (frutas deshidratadas, té deshidratado y especias de cocina) con una ligera preferencia por las frutas deshidratadas, mientras que las personas que no han consumido no lo hacen debido al sabor y al desconocimiento del producto.

Los atributos más importantes para los encuestados al momento de elegir un alimento deshidratado son el precio y el valor nutricional, existiendo una marcada frecuencia mensual para realizar las compras.

Con relación al perfil de los clientes, las personas que consumen alimentos deshidratados tienen una vida saludable, mantienen un estilo de vida activa, están de acuerdo en que éstos son una gran fuente de alimentación y la mayoría están de acuerdo con que los alimentos deshidratados son una buena alternativa para enviar en la lonchera escolar de los niños.

La disposición de pago de los potenciales clientes para los alimentos deshidratados analizados en presentaciones específicas para cada una de sus tres líneas está entre $\$ 1,00$ y $\$ 1,30$.

Para que los productos lleguen en gran medida a los consumidores finales, se planteó una estrategia de marketing conocida como las cuatro $\mathrm{p}$ (producto, precio, plaza y promoción) utilizando la información que se desprende de la investigación de campo, conforme se detalla en la tabla 3. 


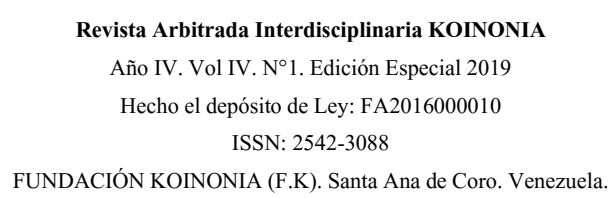

Kleber Patricio Vidal Beltrán; Juan Carlos Erazo Álvarez; Cecilia Ivonne Narváez Zurita

\section{Estrategia de comercialización y ventas}

\section{Tabla 3}

\begin{tabular}{ll} 
Producto & Precio \\
\hline $\begin{array}{l}\text { Elaborados con frutas Ecuatorianas } \\
\text { frescas }\end{array}$ & Precio inferior al del producto extranjero \\
Deshidratado técnico & No superar a precios de productos sustitutos \\
Producto de aspecto agradable & Igualar o disminuir los precios de competencia local \\
Empaque llamativo & Descuentos por volumen \\
Información nutricional & Márgenes de utilidad bajos inicialmente \\
Marca de fácil reconocimiento & Disminución de costos de materia prima por \\
& temporadas \\
Presentaciones tipo snack & Evaluación constante de competitividad \\
Plaza & Promoción \\
Distribución a bajo costo & Publicidad enfocada a personas de entre 20 a 50 años \\
Zona urbana de la ciudad de Cuenca & Publicidad principalmente en redes sociales y radio \\
Tiendas & Para deportistas \\
Minimercados & Para lonchera infantil \\
Supermercados & Producto natural ayuda a mantener vida saludable \\
Distribuidores mayoristas & Banners informativos de productos y valor nutricional \\
Evaluación de crecimiento & Participación en ferias \\
\hline
\end{tabular}

Fuente: Elaboración propia

Para generar una gestión de procesos adecuada proponemos que la distribución física de la planta tenga un modelo de línea de producción que permita coordinar eficientemente las labores, conforme se indica en la figura 1. 
Revista Arbitrada Interdisciplinaria KOINONIA

Año IV. Vol IV. N¹. Edición Especial 2019

Hecho el depósito de Ley: FA2016000010

ISSN: 2542-3088

FUNDACIÓN KOINONIA (F.K). Santa Ana de Coro. Venezuela.

Kleber Patricio Vidal Beltrán; Juan Carlos Erazo Álvarez; Cecilia Ivonne Narváez Zurita

\section{Distribución del local}

\section{Figura 1}

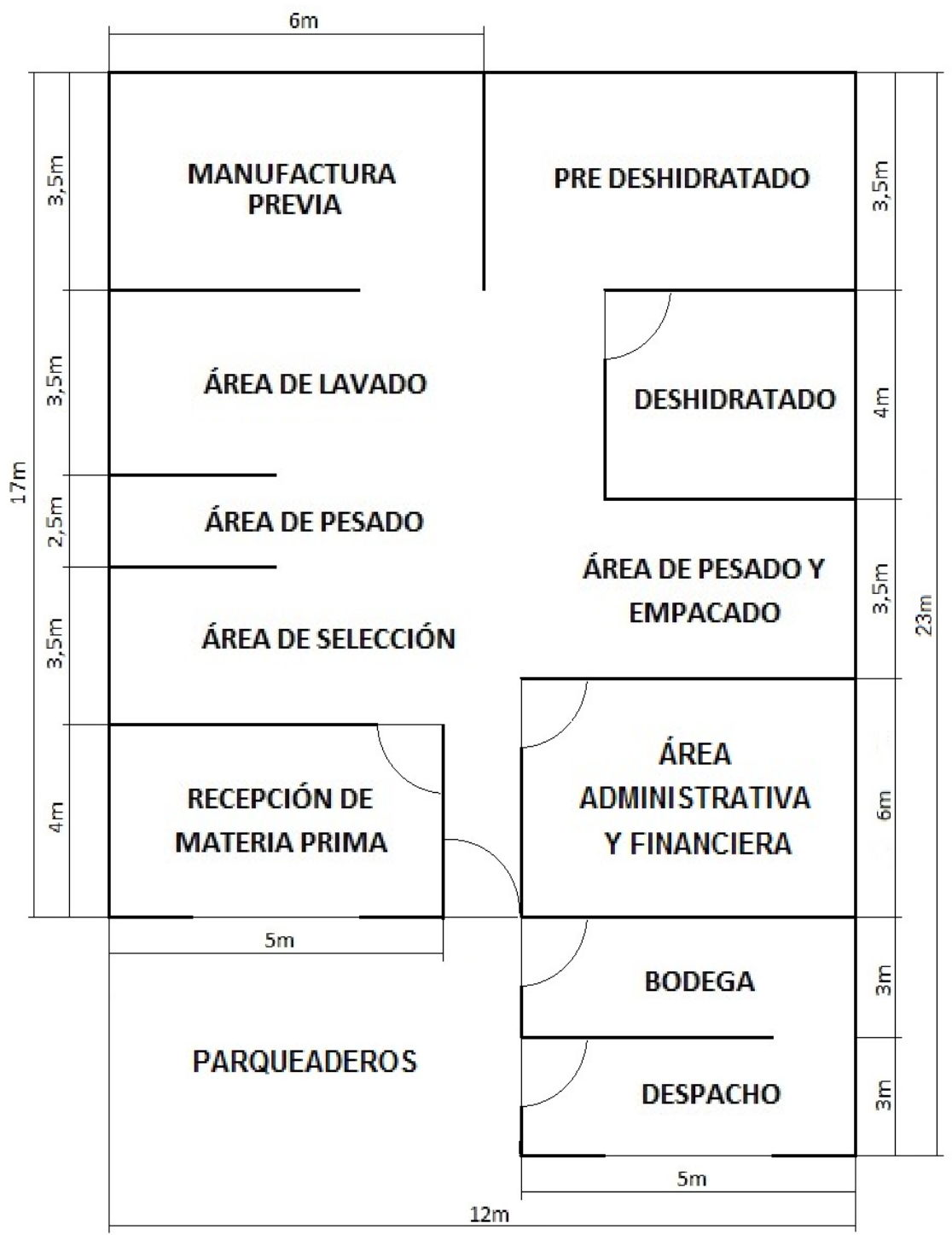

Fuente: Elaboración propia 


\section{Balance de personal}

Para el arranque de la empresa, se consideró el personal básico necesario para cubrir la demanda inicial de productos y la capacidad productiva inicial de la empresa según se muestra en la tabla 4.

\section{Detalle de personal}

\section{Tabla 4}

\begin{tabular}{cllrr} 
Cant. & Cargo & \multicolumn{1}{c}{ Área } & \multicolumn{1}{c}{ Sueldo } & \multicolumn{1}{c}{ Total } \\
\hline $\mathbf{1}$ & Gerente & Administrativo & $\$ 1.000,00$ & $\$ 1.000,00$ \\
$\mathbf{1}$ & Contador & Financiero & $\$ 600,00$ & $\$ 600,00$ \\
$\mathbf{1}$ & Jefe de producción & Producción & $\$ 800,00$ & $\$ 800,00$ \\
$\mathbf{3}$ & Operario & Producción & $\$ 400,00$ & $\$ 1.200,00$ \\
$\mathbf{1}$ & Bodeguero & Producción & $\$ 400,00$ & $\$ 400,00$ \\
& & & Total: & $\$ 4.000,00$
\end{tabular}

\section{Balance de activos}

Los activos necesarios para desarrollar las actividades propias de la empresa manteniendo altos estándares de calidad, higiene, eficacia y eficiencia son los que se presentan en la tabla 5. 


\section{Detalle de activos}

\section{Tabla 5}

$$
\text { Artículo Cant. Valor unitario Valor total }
$$

\begin{tabular}{llcc}
\hline Máquina deshidratadora & 1 & $\$ 1.600,00$ & $\$ 1.600,00$ \\
Nevera & 1 & $\$ 450,00$ & $\$ 450,00$ \\
Cocina de gas & 1 & $\$ 600,00$ & $\$ 600,00$ \\
Máquina selladora & 1 & $\$ 100,00$ & $\$ 100,00$ \\
Balanza de precisión & 2 & $\$ 75,00$ & $\$ 150,00$ \\
Utensilios de cocina & 1 & $\$ 240,00$ & $\$ 240,00$ \\
Tina de lavado & 4 & $\$ 50,00$ & $\$ 200,00$ \\
Mesa de trabajo & 6 & $\$ 100,00$ & $\$ 600,00$ \\
Estación de trabajo & 3 & $\$ 350,00$ & $\$ 1.050,00$ \\
Computador & 2 & $\$ 500,00$ & $\$ 1.000,00$ \\
Impresora multifunción & 1 & $\$ 250,00$ & $\$ 250,00$ \\
Vehículo & 1 & $\$ 12.000,00$ & $\$ 12.000,00$ \\
\multicolumn{1}{c}{ TOTAL: } & & & $\$ 18.240,00$ \\
\hline
\end{tabular}

\section{Flujograma de proceso}

El proceso de deshidratación de frutas desde que la materia prima ingresa a la planta de producción hasta que sale el producto terminado, considerando todos los aspectos necesarios para obtener productos con altos estándares de calidad se muestra en la figura 2. 


\section{Flujograma de proceso}

\section{Figura 2}

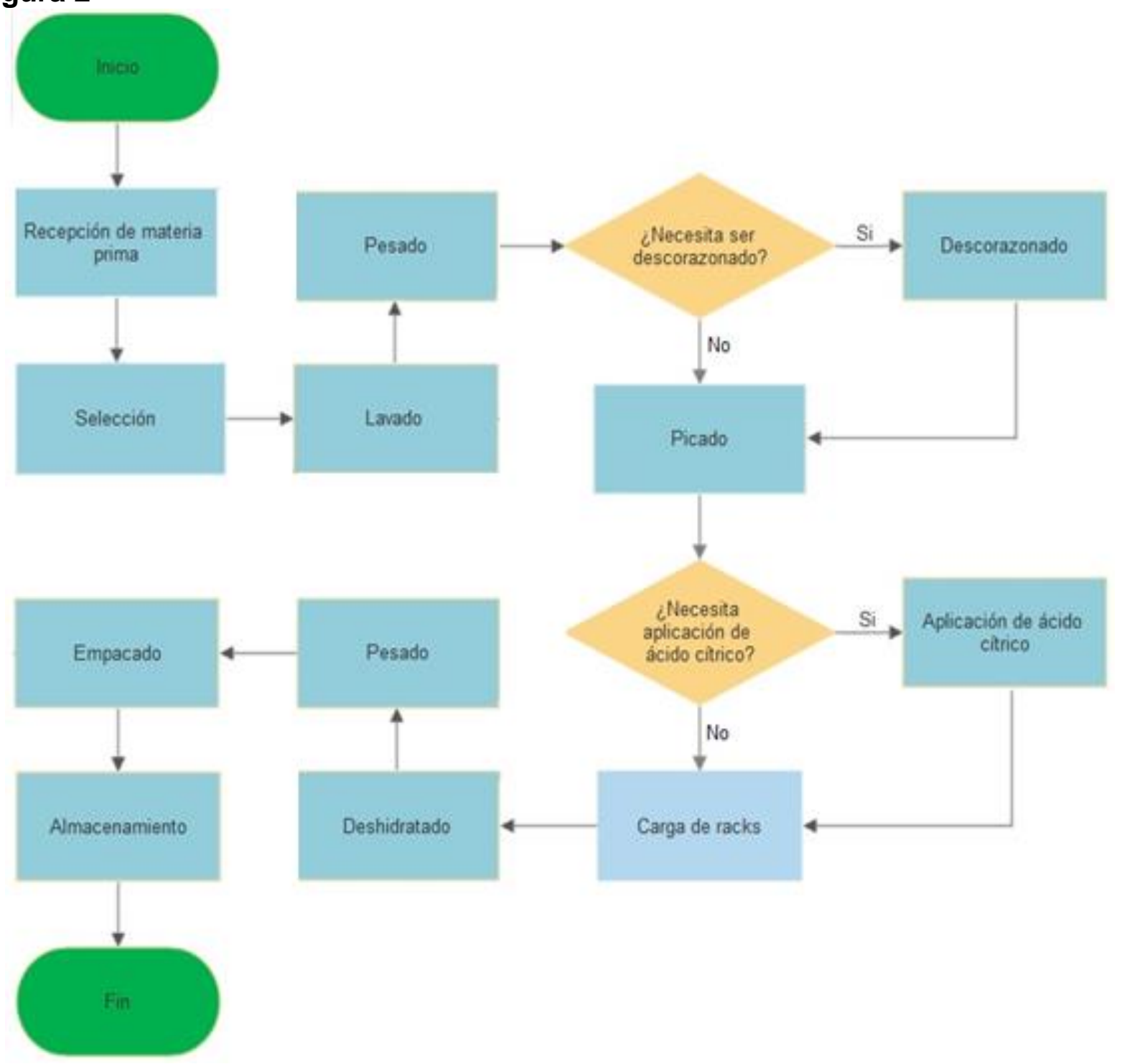

Fuente: Elaboración propia

\section{Análisis económico financiero}

El análisis financiero fue realizado siguiendo las directrices que Sapag (2011) indica en su obra para la formulación y evaluación de proyectos de inversión, para lo cual se ubicaron los valores resultantes de los cálculos mostrados previamente en sus 
respectivas cuentas, mientras que para las cuentas "Ventas netas", "Gastos generales de operación", "Gastos de venta y marketing" y "Otros gastos" que según la opinión de cinco expertos financieros tenían mayor incertidumbre se crearon intervalos de confianza con valores mínimos y máximos que podían tomar en el período de análisis según se puede apreciar en la tabla 6 , luego de lo cual, según la opinión de diez expertos empresariales se realizó el expertizaje a cada una de las seis cuentas, recogiendo sus opiniones sobre los valores asignados en los intervalos de confianza según se muestra en la tabla 7, para así poder aplicar las técnicas de lógica difusa: vaciado de valores, normalización de serie, expertón y contraexpertizaje para atrapar y reducir la incertidumbre de las cuentas analizadas, mostrando sus resultados en las tablas $8,9,10$, 11,12 y 13.

Los valores resultantes fueron utilizados para proyectar y estructurar el primer año de funcionamiento empresarial, para el resto de años analizados, se aplicó un incremento lineal conforme a datos históricos aportados por las correspondientes entidades gubernamentales de control.

El balance general inicial es mostrado en la tabla 15, el estado de resultados es presentado en la tabla 18, el flujo de caja es mostrado en la tabla 19 y el cálculo del valor actual neto VAN y la tasa interna de retorno TIR es presentados en la tabla 21. 


\section{Cuentas contables con intervalos de confianza y promedio simple}

\section{Tabla 6}

Intervalos de confianza

Cuentas

\section{Cota mínima Cota máxima Valor medio}

\begin{tabular}{lrrr}
\hline Ventas netas & $\$ 102.000,00$ & $\$ 110.400,00$ & $\$ 106.200,00$ \\
Costo de ventas & $\$ 43.300,00$ & $\$ 45.000,00$ & $\$ 44.150,00$ \\
Sueldos administrativos & $\$ 19.200,00$ & $\$ 19.200,00$ & $\$ 19.200,00$ \\
Gastos generales de operación & $\$ 500,00$ & $\$ 600,00$ & $\$ 550,00$ \\
Gastos de ventas y marketing & $\$ 25.000,00$ & $\$ 36.000,00$ & $\$ 30.500,00$ \\
Otros gastos & $\$ 1.000,00$ & $\$ 1.100,00$ & $\$ 1.050,00$ \\
Depreciación & $\$ 1.904,10$ & $\$ 1.904,10$ & $\$ 1.904,10$ \\
Gastos financieros & $\$ 2.622,84$ & $\$ 2.622,84$ & $\$ 2.622,84$ \\
Inventario inicial & $\$ 0,00$ & $\$ 0,00$ & $\$ 0,00$ \\
$\quad$ Compras & $\$ 5.000,00$ & $\$ 5.500,00$ & $\$ 5.250,00$ \\
Mano de obra & $\$ 28.800,00$ & $\$ 28.800,00$ & $\$ 28.800,00$ \\
Gastos indirectos de & $\$ 10.000,00$ & $\$ 11.200,00$ & $\$ 10.600,00$ \\
fabricación & & & \\
Inventario final & $-\$ 500,00$ & $-\$ 500,00$ & $-\$ 500,00$ \\
\hline
\end{tabular}




\section{Expertizaje en las cuentas de mayor incertidumbre}

\section{Tabla 7}

\begin{tabular}{|c|c|c|c|c|c|c|c|c|c|c|c|c|}
\hline & \multicolumn{2}{|c|}{ Ventas netas } & \multicolumn{2}{|c|}{$\begin{array}{l}\text { Gastos generales } \\
\text { de operación }\end{array}$} & \multicolumn{2}{|c|}{$\begin{array}{c}\text { Gastos de ventas } \\
\text { y marketing }\end{array}$} & \multicolumn{2}{|c|}{ Otros gastos } & \multicolumn{2}{|c|}{ Compras } & \multicolumn{2}{|c|}{$\begin{array}{c}\text { Gastos indirectos } \\
\text { de fabricación }\end{array}$} \\
\hline & $\begin{array}{l}\text { Cota } \\
\text { menor }\end{array}$ & $\begin{array}{l}\text { Cota } \\
\text { mayor }\end{array}$ & $\begin{array}{l}\text { Cota } \\
\text { menor }\end{array}$ & $\begin{array}{l}\text { Cota } \\
\text { mayor }\end{array}$ & $\begin{array}{l}\text { Cota } \\
\text { menor }\end{array}$ & $\begin{array}{l}\text { Cota } \\
\text { mayor }\end{array}$ & $\begin{array}{l}\text { Cota } \\
\text { menor }\end{array}$ & $\begin{array}{l}\text { Cota } \\
\text { mayor }\end{array}$ & $\begin{array}{l}\text { Cota } \\
\text { menor }\end{array}$ & $\begin{array}{l}\text { Cota } \\
\text { mayor }\end{array}$ & $\begin{array}{l}\text { Cota } \\
\text { menor }\end{array}$ & $\begin{array}{l}\text { Cota } \\
\text { mayor }\end{array}$ \\
\hline Experto 1 & 0,7 & 1 & 0,3 & 0,6 & 0,6 & 0,7 & 0,8 & 0,8 & 0,5 & 0,8 & 0,7 & 0,6 \\
\hline Experto 2 & 0,6 & 0,9 & 0,4 & 0,6 & 0,7 & 0,7 & 0,7 & 0,7 & 0,8 & 0,6 & 0,8 & 0,5 \\
\hline Experto 3 & 0,7 & 0,8 & 0 & 0,6 & 0,8 & 0,8 & 0,8 & 0,8 & 0,7 & 0,5 & 0,7 & 0,6 \\
\hline Experto 4 & 0,6 & 1 & 0,2 & 0,7 & 0,6 & 0,6 & 0,6 & 1 & 0,6 & 0,8 & 0,8 & 0,4 \\
\hline Experto 5 & 0,8 & 0,8 & 0 & 0,6 & 0,6 & 0,5 & 0,8 & 0,9 & 0,4 & 0,4 & 0,7 & 0,5 \\
\hline Experto 6 & 0,7 & 1 & 0,4 & 0,7 & 0,7 & 0,4 & 0,8 & 0,8 & 0,8 & 0,7 & 0,8 & 0,6 \\
\hline Experto 7 & 0,7 & 0,9 & 0,3 & 0,8 & 0,7 & 0,5 & 0,7 & 0,7 & 0,9 & 0,8 & 0,8 & 0,5 \\
\hline Experto 8 & 0,7 & 1 & 0,2 & 0,9 & 0,6 & 0,4 & 0,8 & 0,8 & 0,5 & 0,8 & 0,9 & 0,6 \\
\hline Experto 9 & 0,8 & 0,9 & 0,2 & 0,8 & 0,5 & 0,7 & 0,8 & 1 & 0,5 & 0,6 & 0,8 & 0,4 \\
\hline $\begin{array}{c}\text { Experto } \\
10\end{array}$ & 0,7 & 1 & 0,3 & 0,7 & 0,6 & 0,6 & 0,9 & 0,9 & 0,8 & 0,8 & 0,7 & 0,6 \\
\hline
\end{tabular}




\section{Contraexpertizaje en la cuenta "Ventas netas"}

\section{Tabla 8}

$$
\text { Vaciado de valores Normalización de Experton alpha Contraespertizaje }
$$
la serie

\begin{tabular}{ccccccccc} 
Escala & $\begin{array}{c}\text { Cota } \\
\text { mínima }\end{array}$ & $\begin{array}{c}\text { Cota } \\
\text { máxima }\end{array}$ & $\begin{array}{c}\text { Cota } \\
\text { mínima }\end{array}$ & $\begin{array}{c}\text { Cota } \\
\text { máxima }\end{array}$ & $\begin{array}{c}\text { Cota } \\
\text { mínima }\end{array}$ & $\begin{array}{c}\text { Cota } \\
\text { máxima }\end{array}$ & $\begin{array}{c}\text { Cota } \\
\text { mínima }\end{array}$ & $\begin{array}{c}\text { Cota } \\
\text { máxima }\end{array}$ \\
$\mathbf{0}$ & 0 & 0 & 0,00 & 0,00 & 1,00 & 1,00 & $\$ 110.400,00$ & $\$ 110.400,00$ \\
$\mathbf{0 , 1}$ & 0 & 0 & 0,00 & 0,00 & 1,00 & 1,00 & $\$ 110.400,00$ & $\$ 110.400,00$ \\
$\mathbf{0 , 2}$ & 0 & 0 & 0,00 & 0,00 & 1,00 & 1,00 & $\$ 110.400,00$ & $\$ 110.400,00$ \\
$\mathbf{0 , 3}$ & 0 & 0 & 0,00 & 0,00 & 1,00 & 1,00 & $\$ 110.400,00$ & $\$ 110.400,00$ \\
$\mathbf{0 , 4}$ & 0 & 0 & 0,00 & 0,00 & 1,00 & 1,00 & $\$ 110.400,00$ & $\$ 110.400,00$ \\
$\mathbf{0 , 5}$ & 0 & 0 & 0,00 & 0,00 & 1,00 & 1,00 & $\$ 110.400,00$ & $\$ 110.400,00$ \\
$\mathbf{0 , 6}$ & 2 & 0 & 0,20 & 0,00 & 1,00 & 1,00 & $\$ 110.400,00$ & $\$ 110.400,00$ \\
$\mathbf{0 , 7}$ & 6 & 0 & 0,60 & 0,00 & 0,80 & 1,00 & $\$ 108.720,00$ & $\$ 110.400,00$ \\
$\mathbf{0 , 8}$ & 2 & 2 & 0,20 & 0,20 & 0,20 & 1,00 & $\$ 103.680,00$ & $\$ 110.400,00$ \\
$\mathbf{0 , 9}$ & 0 & 3 & 0,00 & 0,30 & 0,00 & 0,80 & $\$ 102.000,00$ & $\$ 108.720,00$ \\
$\mathbf{1}$ & 0 & 5 & 0,00 & 0,50 & 0 & 0,5 & $\$ 102.000,00$ & $\$ 106.200,00$ \\
& $\mathbf{1 0}$ & $\mathbf{1 0}$ & $\mathbf{1}$ & $\mathbf{1}$ & $\mathbf{0 , 7 0}$ & $\mathbf{0 , 9 3}$ & $\mathbf{\$ 1 0 7 . 8 8 0 , 0 0}$ & $\mathbf{\$ 1 0 9 . 8 1 2 , 0 0}$ \\
\hline
\end{tabular}




\section{Contraexpertizaje en la cuenta "Gastos generales de operación"}

\section{Tabla 9}

$$
\text { Vaciado de valores Normalización de la Experton alpha Contraespertizaje }
$$
serie

\begin{tabular}{ccccccccc} 
Escala & $\begin{array}{c}\text { Cota } \\
\text { mínima }\end{array}$ & $\begin{array}{c}\text { Cota } \\
\text { máxima }\end{array}$ & $\begin{array}{c}\text { Cota } \\
\text { mínima }\end{array}$ & $\begin{array}{c}\text { Cota } \\
\text { máxima }\end{array}$ & $\begin{array}{c}\text { Cota } \\
\text { mínima }\end{array}$ & $\begin{array}{c}\text { Cota } \\
\text { máxima }\end{array}$ & $\begin{array}{c}\text { Cota } \\
\text { mínima }\end{array}$ & $\begin{array}{c}\text { Cota } \\
\text { máxima }\end{array}$ \\
$\mathbf{0}$ & 2 & 0 & 0,20 & 0,00 & 1,00 & 1,00 & $\$ 600,00$ & $\$ 600,00$ \\
$\mathbf{0 , 1}$ & 0 & 0 & 0,00 & 0,00 & 0,80 & 1,00 & $\$ 580,00$ & $\$ 600,00$ \\
$\mathbf{0 , 2}$ & 3 & 0 & 0,30 & 0,00 & 0,80 & 1,00 & $\$ 580,00$ & $\$ 600,00$ \\
$\mathbf{0 , 3}$ & 3 & 0 & 0,30 & 0,00 & 0,50 & 1,00 & $\$ 550,00$ & $\$ 600,00$ \\
$\mathbf{0 , 4}$ & 2 & 0 & 0,20 & 0,00 & 0,20 & 1,00 & $\$ 520,00$ & $\$ 600,00$ \\
$\mathbf{0 , 5}$ & 0 & 0 & 0,00 & 0,00 & 0,00 & 1,00 & $\$ 500,00$ & $\$ 600,00$ \\
$\mathbf{0 , 6}$ & 0 & 4 & 0,00 & 0,40 & 0,00 & 1,00 & $\$ 500,00$ & $\$ 600,00$ \\
$\mathbf{0 , 7}$ & 0 & 3 & 0,00 & 0,30 & 0,00 & 0,60 & $\$ 500,00$ & $\$ 560,00$ \\
$\mathbf{0 , 8}$ & 0 & 2 & 0,00 & 0,20 & 0,00 & 0,30 & $\$ 500,00$ & $\$ 530,00$ \\
$\mathbf{0 , 9}$ & 0 & 1 & 0,00 & 0,10 & 0,00 & 0,10 & $\$ 500,00$ & $\$ 510,00$ \\
$\mathbf{1}$ & 0 & 0 & 0,00 & 0,00 & 0,00 & 0 & $\$ 500,00$ & $\$ 500,00$ \\
& $\mathbf{1 0}$ & $\mathbf{1 0}$ & $\mathbf{1}$ & $\mathbf{1}$ & $\mathbf{0 , 2 3}$ & $\mathbf{0 , 7 0}$ & $\mathbf{\$ 5 2 3 , 0 0}$ & $\$ \mathbf{5 7 0}, \mathbf{0 0}$ \\
\hline
\end{tabular}




\section{Contraexpertizaje en la cuenta "Gastos de ventas y marketing"}

Tabla 10

\begin{tabular}{ccccccccc}
\multicolumn{1}{c}{ Vaciado de valores } & \multicolumn{2}{c}{$\begin{array}{c}\text { Normalización de la } \\
\text { serie }\end{array}$} & \multicolumn{2}{c}{ Experton alpha } & \multicolumn{2}{c}{ Contraespertizaje } \\
\hline Escala & $\begin{array}{c}\text { Cota } \\
\text { mínima }\end{array}$ & $\begin{array}{c}\text { Cota } \\
\text { máxima }\end{array}$ & $\begin{array}{c}\text { Cota } \\
\text { mínima }\end{array}$ & $\begin{array}{c}\text { Cota } \\
\text { máxima }\end{array}$ & $\begin{array}{c}\text { Cota } \\
\text { mínima }\end{array}$ & $\begin{array}{c}\text { Cota } \\
\text { máxima }\end{array}$ & $\begin{array}{c}\text { Cota } \\
\text { mínima }\end{array}$ & $\begin{array}{c}\text { Cota } \\
\text { máxima }\end{array}$ \\
$\mathbf{0}$ & 0 & 0 & 0,00 & 0,00 & 1,00 & 1,00 & $\$ 36.000,00$ & $\$ 36.000,00$ \\
$\mathbf{0 , 1}$ & 0 & 0 & 0,00 & 0,00 & 1,00 & 1,00 & $\$ 36.000,00$ & $\$ 36.000,00$ \\
$\mathbf{0 , 2}$ & 0 & 0 & 0,00 & 0,00 & 1,00 & 1,00 & $\$ 36.000,00$ & $\$ 36.000,00$ \\
$\mathbf{0 , 3}$ & 0 & 0 & 0,00 & 0,00 & 1,00 & 1,00 & $\$ 36.000,00$ & $\$ 36.000,00$ \\
$\mathbf{0 , 4}$ & 0 & 2 & 0,00 & 0,20 & 1,00 & 1,00 & $\$ 36.000,00$ & $\$ 36.000,00$ \\
$\mathbf{0 , 5}$ & 1 & 2 & 0,10 & 0,20 & 1,00 & 0,80 & $\$ 36.000,00$ & $\$ 33.800,00$ \\
$\mathbf{0 , 6}$ & 5 & 2 & 0,50 & 0,20 & 0,90 & 0,60 & $\$ 34.900,00$ & $\$ 31.600,00$ \\
$\mathbf{0 , 7}$ & 3 & 3 & 0,30 & 0,30 & 0,40 & 0,40 & $\$ 29.400,00$ & $\$ 29.400,00$ \\
$\mathbf{0 , 8}$ & 1 & 1 & 0,10 & 0,10 & 0,10 & 0,10 & $\$ 26.100,00$ & $\$ 26.100,00$ \\
$\mathbf{0 , 9}$ & 0 & 0 & 0,00 & 0,00 & 0,00 & 0,00 & $\$ 25.000,00$ & $\$ 25.000,00$ \\
$\mathbf{1}$ & 0 & 0 & 0,00 & 0,00 & 0 & 0 & $\$ 25.000,00$ & $\$ 25.000,00$ \\
& $\mathbf{1 0}$ & $\mathbf{1 0}$ & $\mathbf{1}$ & $\mathbf{1}$ & $\mathbf{0 , 6 4}$ & $\mathbf{0 , 5 9}$ & $\mathbf{\$} 32.040,00$ & $\$ 31.490,00$ \\
\hline
\end{tabular}




\section{Contraexpertizaje en la cuenta "Otros gastos"}

\section{Tabla 11}

\begin{tabular}{|c|c|c|c|c|c|c|c|c|}
\hline & \multicolumn{2}{|c|}{ Vaciado de valores } & \multicolumn{2}{|c|}{$\begin{array}{c}\text { Normalización de la } \\
\text { serie }\end{array}$} & \multicolumn{2}{|c|}{ Experton alpha } & \multicolumn{2}{|c|}{ Contraespertizaje } \\
\hline Escala & $\begin{array}{c}\text { Cota } \\
\text { mínima }\end{array}$ & $\begin{array}{c}\text { Cota } \\
\text { máxima }\end{array}$ & $\begin{array}{c}\text { Cota } \\
\text { mínima }\end{array}$ & $\begin{array}{c}\text { Cota } \\
\text { máxima }\end{array}$ & $\begin{array}{c}\text { Cota } \\
\text { mínima }\end{array}$ & $\begin{array}{c}\text { Cota } \\
\text { máxima }\end{array}$ & $\begin{array}{c}\text { Cota } \\
\text { mínima }\end{array}$ & $\begin{array}{c}\text { Cota } \\
\text { máxima }\end{array}$ \\
\hline 0 & 0 & 0 & 0,00 & 0,00 & 1,00 & 1,00 & $\$ 1.100,00$ & $\$ 1.100,00$ \\
\hline 0,1 & 0 & 0 & 0,00 & 0,00 & 1,00 & 1,00 & $\$ 1.100,00$ & $\$ 1.100,00$ \\
\hline 0,2 & 0 & 0 & 0,00 & 0,00 & 1,00 & 1,00 & $\$ 1.100,00$ & $\$ 1.100,00$ \\
\hline 0,3 & 0 & 0 & 0,00 & 0,00 & 1,00 & 1,00 & $\$ 1.100,00$ & $\$ 1.100,00$ \\
\hline 0,4 & 0 & 0 & 0,00 & 0,00 & 1,00 & 1,00 & $\$ 1.100,00$ & $\$ 1.100,00$ \\
\hline 0,5 & 0 & 0 & 0,00 & 0,00 & 1,00 & 1,00 & $\$ 1.100,00$ & $\$ 1.100,00$ \\
\hline 0,6 & 1 & 0 & 0,10 & 0,00 & 1,00 & 1,00 & $\$ 1.100,00$ & $\$ 1.100,00$ \\
\hline 0,7 & 2 & 2 & 0,20 & 0,20 & 0,90 & 1,00 & $\$ 1.090,00$ & $\$ 1.100,00$ \\
\hline 0,8 & 6 & 4 & 0,60 & 0,40 & 0,70 & 0,80 & $\$ 1.070,00$ & $\$ 1.080,00$ \\
\hline 0,9 & 1 & 2 & 0,10 & 0,20 & 0,10 & 0,40 & $\$ 1.010,00$ & $\$ 1.040,00$ \\
\hline \multirow[t]{2}{*}{1} & 0 & 2 & 0,00 & 0,20 & 0 & 0,2 & $\$ 1.000,00$ & $\$ 1.020,00$ \\
\hline & 10 & 10 & 1 & 1 & 0,77 & 0,84 & $\$ 1.077,00$ & $\$ 1.084,00$ \\
\hline
\end{tabular}




\section{Contraexpertizaje en la cuenta "Compras"}

\section{Tabla 12}

\begin{tabular}{|c|c|c|c|c|c|c|c|c|}
\hline & \multicolumn{2}{|c|}{ Vaciado de valores } & \multicolumn{2}{|c|}{$\begin{array}{c}\text { Normalización de la } \\
\text { serie }\end{array}$} & \multicolumn{2}{|c|}{ Experton alpha } & \multicolumn{2}{|c|}{ Contraespertizaje } \\
\hline Escala & $\begin{array}{l}\text { Cota } \\
\text { mínima }\end{array}$ & $\begin{array}{c}\text { Cota } \\
\text { máxima }\end{array}$ & $\begin{array}{l}\text { Cota } \\
\text { mínima }\end{array}$ & $\begin{array}{c}\text { Cota } \\
\text { máxima }\end{array}$ & $\begin{array}{l}\text { Cota } \\
\text { mínima }\end{array}$ & $\begin{array}{c}\text { Cota } \\
\text { máxima }\end{array}$ & $\begin{array}{l}\text { Cota } \\
\text { mínima }\end{array}$ & $\begin{array}{c}\text { Cota } \\
\text { máxima }\end{array}$ \\
\hline 0 & 0 & 0 & 0,00 & 0,00 & 1,00 & 1,00 & $\$ 5.500,00$ & $\$ 5.500,00$ \\
\hline 0,1 & 0 & 0 & 0,00 & 0,00 & 1,00 & 1,00 & $\$ 5.500,00$ & $\$ 5.500,00$ \\
\hline 0,2 & 0 & 0 & 0,00 & 0,00 & 1,00 & 1,00 & $\$ 5.500,00$ & $\$ 5.500,00$ \\
\hline 0,3 & 0 & 0 & 0,00 & 0,00 & 1,00 & 1,00 & $\$ 5.500,00$ & $\$ 5.500,00$ \\
\hline 0,4 & 1 & 1 & 0,10 & 0,10 & 1,00 & 1,00 & $\$ 5.500,00$ & $\$ 5.500,00$ \\
\hline 0,5 & 3 & 1 & 0,30 & 0,10 & 0,90 & 0,90 & $\$ 5.450,00$ & $\$ 5.450,00$ \\
\hline 0,6 & 1 & 2 & 0,10 & 0,20 & 0,60 & 0,80 & $\$ 5.300,00$ & $\$ 5.400,00$ \\
\hline 0,7 & 1 & 1 & 0,10 & 0,10 & 0,50 & 0,60 & $\$ 5.250,00$ & $\$ 5.300,00$ \\
\hline 0,8 & 3 & 5 & 0,30 & 0,50 & 0,40 & 0,50 & $\$ 5.200,00$ & $\$ 5.250,00$ \\
\hline 0,9 & 1 & 0 & 0,10 & 0,00 & 0,10 & 0,00 & $\$ 5.050,00$ & $\$ 5.000,00$ \\
\hline \multirow[t]{2}{*}{1} & 0 & 0 & 0,00 & 0,00 & 0,00 & 0 & $\$ 5.000,00$ & $\$ 5.000,00$ \\
\hline & 10 & 10 & 1 & 1 & 0,65 & 0,68 & $\$ 5.325,00$ & $\$ 5.340,00$ \\
\hline
\end{tabular}

Contraexpertizaje en la cuenta "Gastos indirectos de fabricación" 


\section{Tabla 13}

Vaciado de valores Normalización de la Experton alpha Contraespertizaje

\begin{tabular}{|c|c|c|c|c|c|c|c|c|}
\hline Escala & $\begin{array}{c}\text { Cota } \\
\text { mínima }\end{array}$ & $\begin{array}{c}\text { Cota } \\
\text { máxima }\end{array}$ & $\begin{array}{c}\text { Cota } \\
\text { mínima }\end{array}$ & $\begin{array}{c}\text { Cota } \\
\text { máxima }\end{array}$ & $\begin{array}{c}\text { Cota } \\
\text { mínima }\end{array}$ & $\begin{array}{c}\text { Cota } \\
\text { máxima }\end{array}$ & $\begin{array}{c}\text { Cota } \\
\text { mínima }\end{array}$ & $\begin{array}{c}\text { Cota } \\
\text { máxima }\end{array}$ \\
\hline 0 & 0 & 0 & 0,00 & 0,00 & 1,00 & 1,00 & $\begin{array}{c}\$ 11.200,0 \\
0\end{array}$ & $\begin{array}{c}\$ 11.200,0 \\
0\end{array}$ \\
\hline 0,1 & 0 & 0 & 0,00 & 0,00 & 1,00 & 1,00 & $\begin{array}{c}\$ 11.200,0 \\
0\end{array}$ & $\begin{array}{c}\$ 11.200,0 \\
0\end{array}$ \\
\hline 0,2 & 0 & 0 & 0,00 & 0,00 & 1,00 & 1,00 & $\begin{array}{c}\$ 11.200,0 \\
0\end{array}$ & $\begin{array}{c}\$ 11.200,0 \\
0\end{array}$ \\
\hline 0,3 & 0 & 0 & 0,00 & 0,00 & 1,00 & 1,00 & $\begin{array}{c}\$ 11.200,0 \\
0\end{array}$ & $\begin{array}{c}\$ 11.200,0 \\
0\end{array}$ \\
\hline 0,4 & 0 & 2 & 0,00 & 0,20 & 1,00 & 1,00 & $\begin{array}{c}\$ 11.200,0 \\
0\end{array}$ & $\begin{array}{c}\$ 11.200,0 \\
0\end{array}$ \\
\hline 0,5 & 0 & 3 & 0,00 & 0,30 & 1,00 & 0,80 & $\begin{array}{c}\$ 11.200,0 \\
0\end{array}$ & $\begin{array}{c}\$ 10.960,0 \\
0\end{array}$ \\
\hline 0,6 & 0 & 5 & 0,00 & 0,50 & 1,00 & 0,50 & $\begin{array}{c}\$ 11.200,0 \\
0\end{array}$ & $\begin{array}{c}\$ 10.600,0 \\
0\end{array}$ \\
\hline 0,7 & 4 & 0 & 0,40 & 0,00 & 1,00 & 0,00 & $\begin{array}{c}\$ 11.200,0 \\
0\end{array}$ & $\begin{array}{c}\$ 10.000,0 \\
0\end{array}$ \\
\hline 0,8 & 5 & 0 & 0,50 & 0,00 & 0,60 & 0,00 & $\begin{array}{c}\$ 10.720,0 \\
0\end{array}$ & $\begin{array}{c}\$ 10.000,0 \\
0\end{array}$ \\
\hline 0,9 & 1 & 0 & 0,10 & 0,00 & 0,10 & 0,00 & $\begin{array}{c}\$ 10.120,0 \\
0\end{array}$ & $\begin{array}{c}\$ 10.000,0 \\
0\end{array}$ \\
\hline 1 & 0 & 0 & 0,00 & 0,00 & 0 & 0 & $\begin{array}{c}\$ 10.000,0 \\
0\end{array}$ & $\begin{array}{c}\$ 10.000,0 \\
0\end{array}$ \\
\hline & 10 & 10 & 1 & 1 & 0,77 & 0,53 & $\begin{array}{c}\$ 10.924,0 \\
0\end{array}$ & $\begin{array}{c}\$ 10.636,0 \\
0\end{array}$ \\
\hline
\end{tabular}




\section{Cuentas contables aplicado expertizaje y contraexpertizaje}

\section{Tabla 14}

$$
\text { contraexpertizaje }
$$

\section{Cuentas}

\begin{tabular}{lrrr}
\hline Ventas netas & $\$ 107.880,00$ & $\$ 109.812,00$ & $\$ 108.846,00$ \\
Costo de ventas & $\$ 44.549,00$ & $\$ 44.276,00$ & $\$ 44.412,50$ \\
Sueldos administrativos & $\$ 19.200,00$ & $\$ 19.200,00$ & $\$ 19.200,00$ \\
Gastos generales de operación & $\$ 523,00$ & $\$ 570,00$ & $\$ 546,50$ \\
Gastos de ventas y marketing & $\$ 32.040,00$ & $\$ 31.490,00$ & $\$ 31.765,00$ \\
Otros gastos & $\$ 1.077,00$ & $\$ 1.084,00$ & $\$ 1.080,50$ \\
Depreciación & $\$ 1.904,10$ & $\$ 1.904,10$ & $\$ 1.904,10$ \\
Gastos financieros & $\$ 2.622,84$ & $\$ 2.622,84$ & $\$ 2.622,84$ \\
Inventario inicial & $\$ 0,00$ & $\$ 0,00$ & $\$ 0,00$ \\
Compras & $\$ 5.325,00$ & $\$ 5.340,00$ & $\$ 5.332,50$ \\
Mano de obra & $\$ 28.800,00$ & $\$ 28.800,00$ & $\$ 28.800,00$ \\
Gastos indirectos de fabricación & $\$ 10.924,00$ & $\$ 10.636,00$ & $\$ 10.780,00$ \\
Inventario final & $-\$ 500,00$ & $-\$ 500,00$ & $-\$ 500,00$ \\
\hline
\end{tabular}

Cota mínima Cota máxima Valor medio

Balance general inicial 


\section{Balance general inicial}

\section{Tabla 15}

\begin{tabular}{lrlr} 
Activos & \multicolumn{3}{l}{ Pasivos } \\
\hline Activos corrientes & \multicolumn{1}{l}{ Pasivos corrientes } \\
Caja y bancos & $\$ 4.950,00$ & Obligaciones financieras & $\$ 13.114,20$ \\
Inventarios & $\$ 5.000,00$ & Proveedores & $\$ 2.000,00$ \\
Total activo corriente & $\$ 9.950,00$ & Obligaciones con empleados & $\$ 4.000,00$ \\
Activos fijos & & Total pasivo corriente & $\$ \mathbf{1 9 . 1 1 4 , 2 0}$ \\
Maquinaria y equipos & $\$ 2.900,00$ & Total pasivo & $\$ \mathbf{1 9 . 1 1 4 , 2 0}$ \\
Muebles y enseres & $\$ 2.090,00$ & & \\
Equipo de computación & $\$ 1.250,00$ & Patrimonio & \\
Vehículo & $\$ 12.000,00$ & Capital social & $\$ 15.175,80$ \\
Adecuaciones de local & $\$ 3.000,00$ & Total patrimonio & \\
Gastos de constitución & $\$ 2.500,00$ & & \\
Total activos fijos & $\$ 23.740,00$ & & \\
Activos de largo plazo & & & $\$ \mathbf{3 4 . 2 9 0 , 0 0}$ \\
Garantía de arriendo & $\$ 600,00$ & & \\
Total activo a largo plazo & $\$ 600,00$ & & \\
Activos totales & $\$ \mathbf{3 4 . 2 9 0 , 0 0}$ & Total pasivo más patrimonio & \\
\hline
\end{tabular}

\section{Costo de ventas}

En la cuenta "costo de ventas" intervienen las subcuentas "Compras" y "Gastos indirectos de fabricación" a las cuales se aplicaron técnicas de lógica difusa para atrapar y reducir la incertidumbre, cuyos resultados se presentan en la tabla 16, así también en la tabla 17 se presentan los valores utilizados en el estado de resultados correspondientes a todo el período de análisis. 
Contraexpertizaje de la cuenta "Costo de ventas"

\section{Tabla 16}

\begin{tabular}{lrrr} 
& \multicolumn{2}{c}{ contraexpertizaje } & \\
Conceptos & Cota mínima & \multicolumn{1}{c}{ Cota máxima } & \multicolumn{1}{c}{ Valor medio } \\
\hline Inventario inicial & $\$ 0,00$ & $\$ 0,00$ & $\$ 0,00$ \\
Compras & $\$ 5.325,00$ & $\$ 5.340,00$ & $\$ 5.332,50$ \\
Mano de obra & $\$ 28.800,00$ & $\$ 28.800,00$ & $\$ 28.800,00$ \\
Gastos indirectos de fabricación & $\$ 10.924,00$ & $\$ 10.636,00$ & $\$ 10.780,00$ \\
Inventario final & $-\$ 500,00$ & $-\$ 500,00$ & $-\$ 500,00$ \\
Total costo de ventas & $\$ \mathbf{4 4 . 5 4 9 , 0 0}$ & $\mathbf{\$ 4 4 . 2 7 6 , 0 0}$ & $\mathbf{\$ 4 4 . 4 1 2 , 5 0}$ \\
\hline
\end{tabular}

Costo de ventas para cálculo del estado de resultados

\section{Tabla 17}

Costo de ventas

\begin{tabular}{lccccc}
\hline Inventario inicial & Año 1 & Año 2 & Año 3 & Año 4 & Año 5 \\
Compras & $\$ 0,00$ & $-\$ 500,00$ & $-\$ 525,00$ & $-\$ 551,25$ & $-\$ 578,81$ \\
Mano de obra & $\$ 5.332,50$ & $\$ 5.599,13$ & $\$ 5.879,08$ & $\$ 6.173,04$ & $\$ 6.481,69$ \\
$\begin{array}{l}\text { Gastos indirectos de } \\
\text { fabricación }\end{array}$ & $\$ 28.800,00$ & $\$ 29.577,60$ & $\$ 30.376,20$ & $\$ 31.196,35$ & $\$ 32.038,65$ \\
Inventario final & $\$ 10.780,00$ & $\$ 11.319,00$ & $\$ 11.884,95$ & $\$ 12.479,20$ & $\$ 13.103,16$ \\
Total costo de ventas & $\$ 500,00$ & $-\$ 525,00$ & $-\$ 551,25$ & $-\$ 578,81$ & $-\$ 607,75$ \\
\hline
\end{tabular}

\section{Estado de resultados}

Como seguimiento de esta actividad fue elaborado el estado de resultados que se presenta en la tabla 18 para un período de cinco años. 


\section{Estado de resultados}

\section{Tabla 18}

\begin{tabular}{|c|c|c|c|c|c|}
\hline & Año 1 & Año 2 & Año 3 & Año 4 & Año 5 \\
\hline \multicolumn{6}{|l|}{ Ingresos } \\
\hline Ventas netas & $\begin{array}{c}\$ 108.846,0 \\
0\end{array}$ & $\begin{array}{c}\$ 114.288,3 \\
0\end{array}$ & $\begin{array}{l}\$ 120.002,7 \\
2\end{array}$ & $\begin{array}{l}\$ 126.002,8 \\
5\end{array}$ & $\begin{array}{c}\$ 132.302,9 \\
9\end{array}$ \\
\hline (-) Costo de ventas & $\$ 44.412,50$ & $\$ 45.470,73$ & $\$ 47.063,98$ & $\$ 48.718,52$ & $\$ 50.436,93$ \\
\hline Utilidad bruta & $\$ 64.433,50$ & $\$ 68.817,58$ & $\$ 72.938,74$ & $\$ 77.284,33$ & $\$ 81.866,06$ \\
\hline \multicolumn{6}{|l|}{ Egresos } \\
\hline (-) Sueldos & $\$ 19.200,00$ & $\$ 19.718,40$ & $\$ 20.250,80$ & $\$ 20.797,57$ & $\$ 21.359,10$ \\
\hline $\begin{array}{l}\text { (-) Gastos generales } \\
\text { de operación }\end{array}$ & $\$ 546,50$ & $\$ 573,83$ & $\$ 602,52$ & $\$ 632,64$ & $\$ 664,27$ \\
\hline $\begin{array}{l}\text { (-) Gastos de ventas y } \\
\text { marketing }\end{array}$ & $\$ 31.765,00$ & $\$ 33.353,25$ & $\$ 35.020,91$ & $\$ 36.771,96$ & $\$ 38.610,56$ \\
\hline (-) Otros gastos & $\$ 1.080,50$ & $\$ 1.134,53$ & $\$ 1.191,25$ & $\$ 1.250,81$ & $\$ 1.313,35$ \\
\hline (-) Deprec & $\$ 1.904,10$ & $\$ 1.904,10$ & $\$ 1.904,10$ & $\$ 1.529,10$ & $\$ 1.529,10$ \\
\hline Utilidad & $\$ 9.937,40$ & $\$ 12.133,48$ & $\$ 13.969,16$ & $\$ 16.302,25$ & $\$ 18.389,67$ \\
\hline pancieros & $\$ 2.622,84$ & $\$ 2$. & $\$ 2.622$ & $\$ 2.622,84$ & $\$ 2.622,84$ \\
\hline $\begin{array}{l}\text { Utilidad antes de } \\
\text { impuestos y repartición } \\
\text { de utilidades }\end{array}$ & $\$ 7.314,56$ & $\$ 9.510,64$ & $\$ 11.346,32$ & $\$ 13.679,41$ & $\$ 15.766,83$ \\
\hline $\begin{array}{l}\text { Participación de } \\
\text { utilidades a } \\
\text { trabajadores } 15 \%\end{array}$ & $\$ 1.270,96$ & $\$ 1.426,60$ & $\$ 1.701,95$ & $\$ 2.051,91$ & $\$ 2.365,02$ \\
\hline & $\$ 152$ & & $\$ 1.36$ & $\$ 1.641$ & $\$ 1.892,02$ \\
\hline Utilidad neta & $\$ 5.891,09$ & $\$ 6.942,76$ & $\$ 8.282,81$ & $\$ 9.985,97$ & $\$ 11.509,79$ \\
\hline
\end{tabular}

\section{Flujo de caja}

En la tabla 19 se presenta el flujo de caja que es un valioso indicador de la liquidez de la unidad de análisis debido a que muestra las entradas y salidas de efectivo en un periodo determinado incluidos los rubros de inversión necesaria para la creación empresarial. 


\section{Flujo de caja con datos obtenidos del expertizaje y contraexpertizaje}

\section{Tabla 19}

\begin{tabular}{|c|c|c|c|c|c|c|}
\hline & Año 0 & Año 1 & Año 2 & Año 3 & Año 4 & Año 5 \\
\hline Saldo inicial de caja & & $\$ 1.385,80$ & & & & \\
\hline $\begin{array}{l}\text { Total ingresos } \\
\text { operativos } \\
\text { Egresos }\end{array}$ & & $\$ 108.846,00$ & $\$ 114.288,30$ & $\$ 120.002,72$ & $\$ 126.002,85$ & $\$ 132.302,99$ \\
\hline $\begin{array}{l}\text { (-) Costo de } \\
\text { ventas }\end{array}$ & & $\$ 44.412,50$ & $\$ 45.470,73$ & $\$ 47.063,98$ & $\$ 48.718,52$ & $\$ 50.436,93$ \\
\hline $\begin{array}{l}\text { (-) Sueldos } \\
\text { administrativos }\end{array}$ & & $\$ 19.200,00$ & $\$ 19.718,40$ & $\$ 20.250,80$ & $\$ 20.797,57$ & $\$ 21.359,10$ \\
\hline $\begin{array}{l}\text { (-) Gastos } \\
\text { generales de } \\
\text { operación }\end{array}$ & & $\$ 546,50$ & $\$ 573,83$ & $\$ 602,52$ & $\$ 632,64$ & $\$ 664,27$ \\
\hline $\begin{array}{l}(-) \text { Gastos de } \\
\text { ventas y } \\
\text { marketing }\end{array}$ & & $\$ 31.765,00$ & $\$ 33.353,25$ & $\$ 35.020,91$ & $\$ 36.771,96$ & $\$ 38.610,56$ \\
\hline (-) Otros gastos & & $\$ 1.080,50$ & $\$ 1.134,53$ & $\$ 1.191,25$ & $\$ 1.250,81$ & $\$ 1.313,35$ \\
\hline $\begin{array}{l}\text { (-) Depreciación } \\
\text { maquinaria y } \\
\text { mobiliario }\end{array}$ & & $\$ 449,10$ & $\$ 449,10$ & $\$ 449,10$ & $\$ 449,10$ & $\$ 449,10$ \\
\hline $\begin{array}{l}\text { (-) Depreciación } \\
\text { equipo } \\
\text { informático }\end{array}$ & & $\$ 375,00$ & $\$ 375,00$ & $\$ 375,00$ & $\$ 0,00$ & $\$ 0,00$ \\
\hline $\begin{array}{l}\text { (-) Depreciación } \\
\text { vehículos }\end{array}$ & & $\$ 1.080,00$ & $\$ 1.080,00$ & $\$ 1.080,00$ & $\$ 1.080,00$ & $\$ 1.080,00$ \\
\hline Total egresos & & $-\$ 98.908,60$ & - & - & - & - \\
\hline operativos & & & $\$ 102.154,83$ & $\$ 106.033,55$ & $\$ 109.700,61$ & $\$ 113.913,32$ \\
\hline Utilidad operacional & & $\$ 9.937,40$ & $\$ 12.133,48$ & $\$ 13.969,16$ & $\$ 16.302,25$ & $\$ 18.389,67$ \\
\hline $\begin{array}{l}\text { (-) Inversión en } \\
\text { activos } \\
\text { (-) Tramites y } \\
\text { gastos de activo }\end{array}$ & $\begin{array}{c}- \\
\$ 18.240,00 \\
-\$ 5.500,00\end{array}$ & & & & & \\
\hline $\begin{array}{l}\text { Aporte de } \\
\text { accionistas }\end{array}$ & $\$ 15.175,80$ & & & & & \\
\hline $\begin{array}{l}\text { Préstamo } \\
\text { bancario }\end{array}$ & $\$ 9.950,00$ & & & & & \\
\hline $\begin{array}{l}\text { Amortización de } \\
\text { deuda }\end{array}$ & & $-\$ 2.622,84$ & $-\$ 2.622,84$ & $-\$ 2.622,84$ & $-\$ 2.622,84$ & $-\$ 2.622,84$ \\
\hline $\begin{array}{l}\text { Saldo efectivo } \\
\text { anual }\end{array}$ & & $\$ 7.314,56$ & $\$ 9.510,64$ & $\$ 11.346,32$ & $\$ 13.679,41$ & $\$ 15.766,83$ \\
\hline $\begin{array}{l}\text { Saldo neto de } \\
\text { efectivo CAJA }\end{array}$ & $\$ 1.385,80$ & $\$ 4.691,72$ & $\$ 6.887,80$ & $\$ 8.723,48$ & $\$ 11.056,57$ & $\$ 13.143,99$ \\
\hline
\end{tabular}




\section{Flujo de caja con datos obtenidos del promedio simple aplicado al intervalo de confianza}

\section{Tabla 20}

\begin{tabular}{|c|c|c|c|c|c|c|}
\hline & Año 0 & Año 1 & Año 2 & Año 3 & Año 4 & Año 5 \\
\hline Saldo inicial de caja & & $\$ 1.385,80$ & & & & \\
\hline $\begin{array}{l}\text { Total ingresos } \\
\text { operativos } \\
\text { Egresos }\end{array}$ & & $\$ 106.200,00$ & $\$ 111.510,00$ & $\$ 117.085,50$ & $\$ 122.939,78$ & $\$ 129.086,76$ \\
\hline (-) Costo de ventas & & $\$ 46.813,75$ & $\$ 45.195,10$ & $\$ 46.774,57$ & $\$ 48.414,65$ & $\$ 50.117,86$ \\
\hline $\begin{array}{l}\text { (-) Sueldos } \\
\text { administrativos }\end{array}$ & & $\$ 19.200,00$ & $\$ 19.718,40$ & $\$ 20.250,80$ & $\$ 20.797,57$ & $\$ 21.359,10$ \\
\hline $\begin{array}{l}\text { (-) Gastos } \\
\text { generales de } \\
\text { operación }\end{array}$ & & $\$ 550,00$ & $\$ 577,50$ & $\$ 606,38$ & $\$ 636,69$ & $\$ 668,53$ \\
\hline $\begin{array}{l}\text { (-) Gastos de } \\
\text { ventas y marketing }\end{array}$ & & $\$ 30.500,00$ & $\$ 32.025,00$ & $\$ 33.626,25$ & $\$ 35.307,56$ & $\$ 37.072,94$ \\
\hline (-) Otros gastos & & $\$ 1.050,00$ & $\$ 1.102,50$ & $\$ 1.157,63$ & $\$ 1.215,51$ & $\$ 1.276,28$ \\
\hline $\begin{array}{l}\text { (-) Depreciación } \\
\text { maquinaria y } \\
\text { mobiliario }\end{array}$ & & $\$ 449,10$ & $\$ 449,10$ & $\$ 449,10$ & $\$ 449,10$ & $\$ 449,10$ \\
\hline $\begin{array}{l}\text { (-) Depreciación } \\
\text { equipo informático }\end{array}$ & & $\$ 375,00$ & $\$ 375,00$ & $\$ 375,00$ & $\$ 0,00$ & $\$ 0,00$ \\
\hline $\begin{array}{l}\text { (-) Depreciación } \\
\text { vehículos }\end{array}$ & & $\$ 1.080,00$ & $\$ 1.080,00$ & $\$ 1.080,00$ & $\$ 1.080,00$ & $\$ 1.080,00$ \\
\hline $\begin{array}{l}\text { Total egresos } \\
\text { operativos }\end{array}$ & & $\$ 100.017,85$ & $\$ 100 . \overline{-} 22,60$ & $\$ 104.319,72$ & $\$ 107.901,08$ & $\$ 112.023,82$ \\
\hline Utilidad operacional & & $\$ 6.182,15$ & $\$ 10.987,40$ & $\$ 12.765,78$ & $\$ 15.038,70$ & $\$ 17.062,95$ \\
\hline $\begin{array}{l}\text { (-) Inversión en } \\
\text { activos } \\
\text { (-) Tramites y } \\
\text { gastos de activo }\end{array}$ & $\begin{array}{c}- \\
\$ 18.240,00 \\
-\$ 5.500,00\end{array}$ & & & & & \\
\hline $\begin{array}{l}\text { Aporte de } \\
\text { accionistas } \\
\text { Préstamo bancario }\end{array}$ & $\begin{array}{c}\$ 15.175,80 \\
\$ 9.950,00\end{array}$ & & & & & \\
\hline $\begin{array}{l}\text { Amortización de } \\
\text { deuda }\end{array}$ & & $-\$ 2.622,84$ & $-\$ 2.622,84$ & $-\$ 2.622,84$ & $-\$ 2.622,84$ & $-\$ 2.622,84$ \\
\hline $\begin{array}{l}\text { Saldo efectivo } \\
\text { anual }\end{array}$ & & $\$ 3.559,31$ & $\$ 8.364,56$ & $\$ 10.142,94$ & $\$ 12.415,86$ & $\$ 14.440,11$ \\
\hline $\begin{array}{l}\text { Saldo neto de } \\
\text { efectivo CAJA }\end{array}$ & $\$ 1.385,80$ & $\$ 936,47$ & $\$ 5.741,72$ & $\$ 7.520,10$ & $\$ 9.793,02$ & $\$ 11.817,27$ \\
\hline
\end{tabular}




\section{Cálculo del valor actual neto y de la tasa interna de retorno}

El valor actual neto VAN indica cuanto va a ganar la empresa una vez recuperada la inversión mientras que la tasa interna de retorno TIR indica cual es la rentabilidad que va a tener el negocio conforme se aprecia en la tabla 21, para dicho cálculo se utilizaron los resultados de los flujos de caja con mostrados en las tablas 19 y 20.

\section{Resultados de VAN y TIR}

\section{Tabla 21}

\begin{tabular}{ccc} 
& Método tradicional & $\begin{array}{c}\text { Utilizando lógica } \\
\text { difusa }\end{array}$ \\
\hline TIR & $10 \%$ & $19 \%$ \\
VAN & $\$ 133,71$ & $\$ 6.453,67$ \\
\hline
\end{tabular}

\section{Análisis de resultados}

Comparando los resultados mostrados en la tabla 22 obtenidos al aplicar tanto el método tradicional como las técnicas de lógica difusa para el cálculo de los indicadores financieros de la presente unidad de análisis se evidencia un considerable aumento en la rentabilidad durante el periodo de análisis.

\section{Variación de resultados de VAN, TIR y utilidades operativas}

\section{Tabla 22}

\begin{tabular}{lrr} 
& \multicolumn{1}{c}{$\begin{array}{c}\text { Método } \\
\text { tradicional }\end{array}$} & $\begin{array}{r}\text { Utilizando lógica } \\
\text { difusa }\end{array}$ \\
\hline TIR & $10 \%$ & $19 \%$ \\
VAN & $\$ 133,71$ & $\$ 6.453,67$ \\
Utilidad operativa año 1 & $\$ 6.182,15$ & $\$ 9.937,40$ \\
Utilidad operativa año 2 & $\$ 10.987,40$ & $\$ 12.133,48$ \\
Utilidad operativa año 3 & $\$ 12.765,78$ & $\$ 13.969,16$ \\
Utilidad operativa año 4 & $\$ 15.038,70$ & $\$ 16.302,25$ \\
Utilidad operativa año 5 & $\$ 17.062,95$ & $\$ 18.389,67$ \\
\hline
\end{tabular}




\section{Variación de resultados de VAN, TIR y utilidades operativas}

\section{Figura 3}

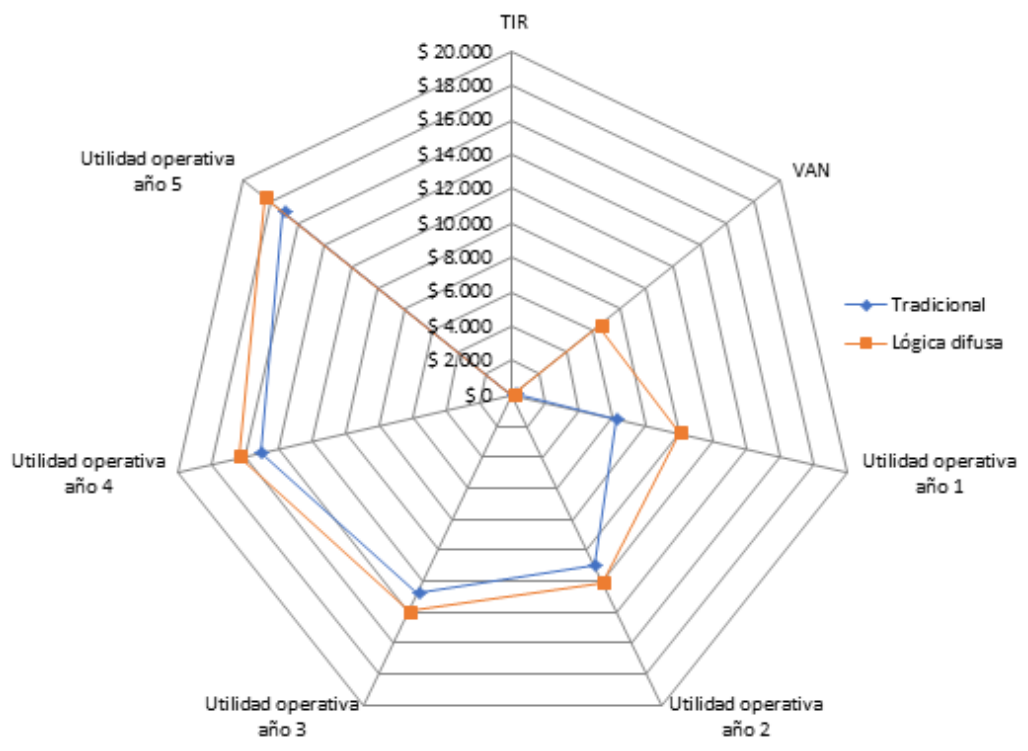

En efecto, al comparar los resultados mostrados en la tabla 23 obtenidos al aplicar tanto el método tradicional como las técnicas de lógica difusa para el cálculo de las cuentas que mayor incertidumbre presentan, se evidencia que con una ligera variación en la asignación de recursos entre cuentas contables se puede optimizar la rentabilidad.

\section{Variación en las cuentas contables}

\section{Tabla 23}

\begin{tabular}{lrrr}
\multicolumn{1}{c}{ Cuentas } & \multicolumn{1}{c}{$\begin{array}{c}\text { Método } \\
\text { tradicional }\end{array}$} & \multicolumn{1}{c}{$\begin{array}{c}\text { Utilizando } \\
\text { lógica difusa }\end{array}$} & $\begin{array}{c}\text { Variación } \\
\text { porcentual }\end{array}$ \\
\hline Ventas netas & $\$ 106.200,00$ & $\$ 108.846,00$ & $2,49 \%$ \\
Gastos generales de operación & $\$ 550,00$ & $\$ 546,50$ & $-0,64 \%$ \\
Gastos de ventas y marketing & $\$ 30.500,00$ & $\$ 31.765,00$ & $4,15 \%$ \\
Otros gastos & $\$ 1.050,00$ & $\$ 1.080,50$ & $2,90 \%$ \\
Compras & $\$ 5.250,00$ & $\$ 5.332,50$ & $1,57 \%$ \\
Gastos indirectos de fabricación & $\$ 10.600,00$ & $\$ 10.780,00$ & $1,70 \%$ \\
\hline
\end{tabular}




\section{Variación en las cuentas contables}

\section{Figura 4}

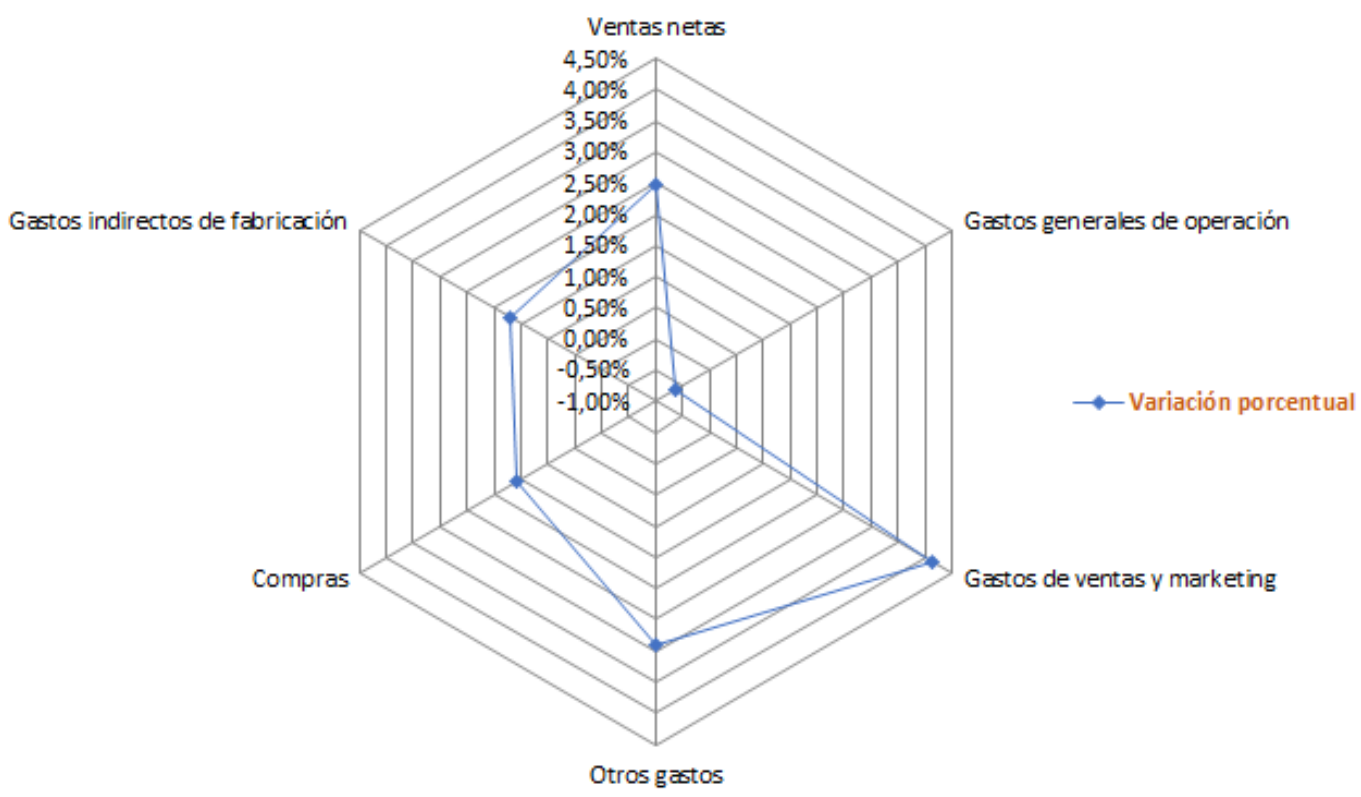

\section{CONCLUSIONES}

En la presente investigación se ha logrado realizar una evaluación financiera a un proyecto de inversión funcional utilizando dos alternativas, el método tradicional de cálculo estático en el que se asignan valores promedio a las cuentas contables que presentan incertidumbre y el método de lógica difusa en el cual a los datos se les somete a técnicas dinámicas de expertizaje y contraexpertizaje para atrapar y reducir dicha incertidumbre.

Aplicando el método tradicional de evaluación financiera se obtuvo únicamente un valor actual neto de $\$ 133,71$ y una tasa interna de retorno del $10 \%$, mientras que al utilizar las técnicas de lógica difusa se observó que la rentabilidad de la empresa aumentó considerablemente obteniendo un valor actual neto es de $\$ 6.453,67$ y una tasa interna de retorno del 19\%, evidenciando que mediante la utilización de las técnicas de lógica difusa se logró optimizar la asignación de recursos a cada una de las cuentas contables que comúnmente presenta gran incertidumbre. 
De lo expuesto se desprende que el emprendimiento es factible de implementar ya que de los indicadores financieros presentan utilidades atractivas para los inversionistas.

Se analizaron los componentes del proyecto de inversión, identificando la estructura organizacional necesaria, estableciendo las estrategias de marketing, comercialización y ventas.

Así también, se realizaron balances de personal y de activos fijos obteniendo un detalle de los recursos necesarios para el funcionamiento del proyecto.

Al mismo tiempo se estableció la distribución óptima del local y el flujograma del proceso productivo de una manera técnica con objeto de optimizar los tiempos y movimientos mediante líneas de producción.

\section{REFERENCIAS CONSULTADAS}

1. Andía, W., y Paucara, E. (2013). Los planes de negocio y los proyectos de inversión: similitudes y diferencias. Industrial Data.

2. ANFAB. (2019). Asociación Nacional de Fabricantes de Alimentos y Bebidas. Recuperado de https://anfab.com/wp/anfab/.

3. Bravo, C., y Cardenas, E. (2016). Estudio comparativo entre el plan de negocios y el método CANVAS como herramientas de decisión para el emprendedor. Caso de análisis: Emprendimientos liderados por la COINCE y la CHV (Tesis de Magister). Quito: Escuela Politecnica Nacional.

4. Castillejo, L. (2015). Plan de negocios. Editorial Macro.

5. CEASE Centro de apoyo al sector empresarial. (2011). Elaboración de plan de negocios para MYPE. CEASE.

6. Corporación Financiera Nacional. (2017). Sector manufacturero alimentos y bebidas. Ficha sectorial, 16.

7. Chirinos, A. (2016). La innovación como factor clave de éxito en la gerencia de las empresas de producción social venezolana. CIENCIAMATRIA, 2(2), 97-106. Recuperado a partir http://cienciamatriarevista.org.ve/index.php/cm/article/view/55 
8. Décaro, L. (2015). Plan de negocios. México: Universidad autónoma del estado de México CU Zampango.

9. Dias, E. (2014). Plan de negocios Tarqutec: cerámica de diseño. Mendoza: Universidad nacional de Cuyo.

10. Flórez, J. (2017). Proyectos de inversión para las PYME. ECOE Ediciones.

11. Goercke Villarreal, J., Erazo Álvarez, J., y Narváez Zurita, C. (2019). Plan de negocio, proyecto constructora Bella Terra en la ciudad de Cuenca, Ecuador. Visionario Digital, 3(2.2), 173-191. Recuperado de https://doi.org/10.33262/visionariodigital.v3i2.2.629.

12. González Astudillo, X. R., Luna Altamirano, K. A., Erazo Álvarez, J. C., y Sarmiento Espinoza, W. H. (2019). Recuperación de cartera bajo el enfoque de subconjuntos borrosos. Ciencia Digital, 163.

13. López, P., y Fachelli, S. (2015). Metodología de la investigación social cuantitativa. Barcelona: Universidad Autónoma de Barcelona.

14. Martínez, L., \& El Kadi, O. (2019). Logística Integral y Calidad Total, Filosofía de Gestión Organizacional orientadas al cliente. Revista Arbitrada Interdisciplinaria Koinonía, 4(7), 202-232. doi:http://dx.doi.org/10.35381/r.k.v4i7.201

15. National Financial Corporation. (2017). Food and beverage manufacturing sector. Sector file, 16.

16. Revista EKOS. (2018). Industria de alimentos y bebidas: la mayor industria del país. EKOS.

17. Rico, M., y Tinto, J. (2008). Matemática borrosa: algunas aplicaciones en las ciencias económicas, administrativas y contables. Contaduría Universidad de Antioquía.

18. Sánchez Agila, G. V., Luna Altamirano, K. A., Narváez Zurita, C. I., y Erazo Álvarez, J. C. (2019). Presupuesto por proyectos bajo la perspectiva de sub conjuntos borrosos. Ciencia Digital, 48.

19. Sapag, N. (2011). Proyectos de inversión formulación y evaluación. Chile: Pearson. 


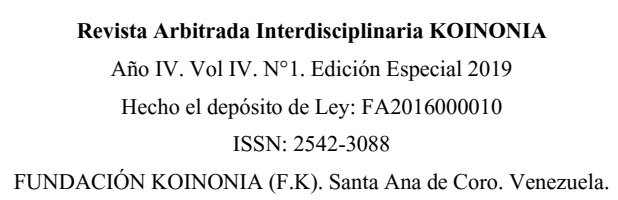

Kleber Patricio Vidal Beltrán; Juan Carlos Erazo Álvarez; Cecilia Ivonne Narváez Zurita

20.Servicio de Rentas Internas. (2019). Catastros. Recuperado de http://www.sri.gob.ec/web/guest/catastros.

21. Viñán, J., Puente, M., Ávalos, J., y Córdova, J. (2018). Proyectos de inversión un enfoque práctico. Chimborazo: ESPOCH.

22. Weinberger, K. (2009). Plan de negocios herramienta para evaluar la viabilidad de un negocio. USAID.

\section{REFERENCES CONSULTED}

1. Andía, W., \& Paucara, E. (2013). Business plans and investment projects: similarities and differences. Industrial Data.

2. ANFAB. (2019). National Association of Food and Beverage Manufacturers. Retrieved from https://anfab.com/wp/anfab/.

3. Bravo, C., \& Cardenas, E. (2016). Comparative study between the business plan and the CANVAS method as decision tools for the entrepreneur. Case study: Entrepreneurships led by COINCE and CHV (Magister's Thesis). Quito: National Polytechnic School.

4. Castillejo, L. (2015). Business plan. Editorial Macro.

5. CEASE Business support center. (2011). Development of business plan for MYPE. CEASE.

6. Chirinos, A. (2016). La innovación como factor clave de éxito en la gerencia de las empresas de producción social venezolana. CIENCIAMATRIA, 2(2), 97-106. Recuperado a partir de http://cienciamatriarevista.org.ve/index.php/cm/article/view/55

7. Décaro, L. (2015). Business plan. Mexico: Autonomous University of the State of Mexico CU Zampango.

8. Dias, E. (2014). Tarqutec business plan: ceramic design. Mendoza: National University of Cuyo.

9. Flórez, J. (2017). Investment projects for SMEs. ECOE Editions. 
10. Goercke Villarreal, J., Erazo Álvarez, J., \& Narváez Zurita, C. (2019). Business plan, Bella Terra construction project in the city of Cuenca, Ecuador. Digital Visionary, $\quad 3 \quad(2.2), \quad 173-191 . \quad$ Retrieved from https://doi.org/10.33262/visionariodigital.v3i2.2.629.

11. González Astudillo, X. R., Luna Altamirano, K. A., Erazo Álvarez, J. C., \& Sarmiento Espinoza, W. H. (2019). Portfolio recovery under the focus of fuzzy subsets. Digital Science, 163.

12. López, P., \& Fachelli, S. (2015). Methodology of quantitative social research. Barcelona: Autonomous University of Barcelona.

13. Martínez, L., \& El Kadi, O. (2019). Logística Integral y Calidad Total, Filosofía de Gestión Organizacional orientadas al cliente. Revista Arbitrada Interdisciplinaria Koinonía, 4(7), 202-232. doi:http://dx.doi.org/10.35381/r.k.v4i7.201

14. National Financial Corporation. (2017). Food and beverage manufacturing sector. Sector file, 16.

15. EKOS Magazine. (2018). Food and beverage industry: the largest industry in the country. EKOS.

16. Rico, M., \& Tinto, J. (2008). Blurred mathematics: some applications in economic, administrative and accounting sciences. Accounting University of Antioquia.

17. Sánchez Agila, G. V., Luna Altamirano, K. A., Narváez Zurita, C. I., \& Erazo Álvarez, J. C. (2019). Budget for projects from the perspective of fuzzy sub sets. Digital Science, 48.

18. Sapag, N. (2011). Investment projects formulation and evaluation. Chile: Pearson.

19. Internal Revenue Service. (2019). Cadastre Recovered from http://www.sri.gob.ec/web/guest/catastros.

20. Viñán, J., Puente, M., Ávalos, J., \& Córdova, J. (2018). Investment projects a practical approach. Chimborazo: ESPOCH.

21. Weinberger, K. (2009). Business plan tool to assess the viability of a business. USAID. 
Revista Arbitrada Interdisciplinaria KOINONIA

Año IV. Vol IV. $N^{\circ} 1$. Edición Especial 2019

Hecho el depósito de Ley: FA2016000010

ISSN: $2542-3088$

FUNDACIÓN KOINONIA (F.K). Santa Ana de Coro. Venezuela.

Kleber Patricio Vidal Beltrán; Juan Carlos Erazo Álvarez; Cecilia Ivonne Narváez Zurita

(C2019 por el autor. Este artículo es de acceso abierto y distribuido según los términos y condiciones de la licencia Creative Commons Atribución-NoComercial-Compartirlgual 4.0 Internacional (CC BY-NC-SA

4.0) (https://creativecommons.org/licenses/by-nc-sa/4.0/). 